\title{
Juvenile Sexual Offending: An EU Prevalence and State Response Study: Study Protocol
}

\author{
Etain Quigley $^{1 *}$, Shane Conaty ${ }^{1}$, Katie Kirkwood ${ }^{1}$ \\ ${ }^{1}$ Department of Law, New House, Maynooth University, Maynooth, Co. Kildare, Ireland
}

\begin{abstract}
Background: Juvenile sexual offending is an area that has been largely under-researched to date and this has resulted in very little and sometimes conflicting research being published in the area. The dearth of empirical data in the space is concerning as it suggests that policy may not be underpinned by an empirical framework and this has far reaching implications for the development of laws, intervention programmes and the management of young people accused/convicted of a juvenile sexual offence. Moreover, the lack of an evidence-based framework has the potential to contribute to misinformation amongst the public who may be relying upon anecdotal news reports and exaggerated media representations.
\end{abstract}

Methods/Design: This study will use a survey to collect the same data from each European member state with the aim of generating comparable data. The first step in the design process was to design a typology of juvenile sexual offences so the data collected represents the same offences across each jurisdiction. The second step in the design process is to design a survey, using the typology, to collect data across each member country.

Discussion: This study aims to take a first step towards generating comparable data across each member state. As such this project will be the first to generate accurate comparable data on the prevalence of juvenile sexual offending across each EU Member State and data on how each Member State reacts to juvenile sexual offending.

Keywords: Juvenile sexual offending, juvenile sexual offending programmes, young offenders, sexual offending

\section{Background}

Within criminal justice systems the term juvenile is used to refer to individuals who have not reached adulthood. The age span related to the term juvenile varies across jurisdictions and indeed has varied across time. For example, in Ireland under the 1908 Act the age of criminal responsibility, that is the age at which a child was deemed to have capacity to know right from wrong and thus could be held accountable for their offending behaviour, was 7 years of age. This changed with the enactment of the Children Act 2001, which resulted in the age of criminal responsibility in Ireland being raised to the age of 12 years of age. Only to change again in 2006 with an amendment to the 2001 Act which reduced the age of criminal responsibility to 10 years for more serious offences whilst leaving it at 12 years for all other

\footnotetext{
* Correspondence to Dr Etain Quigley, Department of Law, Maynooth University, Ireland
}

Email: etain.quigley@mu.ie

Social Science Protocols, July 2021, 1-8.

http://dx.doi.org/10.7565/ssp.v4.5353 
offences. In Ireland, and according to the 2001 Act, the age at which a young person is deemed to be an adult before the law is eighteen.

The term juvenile is used in the majority of international, European, and national instruments to describe an individual under 18 years of age (Dunkel, 2014). This is due to those under 18 years of age as having been identified as not being fully emotionally or behaviourally developed (ibid). However, contemporary neuroscience suggests that emotional and behavioural maturity is not reached until much later, approximately 25 years (Berryessat et al, 2020), and indeed this science is increasingly being used as evidence before the criminal courts (Shen, 2012). This applies equally to juvenile sexual offending whereby Vitacco et al (2009) discuss the developmental changes experienced by young people, arguing that this must be considered when dealing with juveniles who sexually offend. There is a gradual shift in this space, for example, Germany treats young offenders up to the age of 21 years of age differently when compared to adults. However, such instruments as the UN Convention on the Rights of the Child, an international instrument ratified by all EU Member States, continues to recognise a child as an individual under 18 years of age (UNCRC, 1989).

The above section highlights the variation and complexity in terms of age of criminal responsibility and age at which a juvenile is no longer considered a juvenile and is treated like an adult in the various criminal justice systems across the EU. How a jurisdiction defines a juvenile has serious implications for how a juvenile offender is treated within the system, in terms of both progression through the system and sentencing for the offence committed. Indeed, the more serious the offence the greater the implications. Juveniles who commit sexual offences are particularly vulnerable within the system due to the seriousness of the offence. Sexual offending is defined as 'any sexual interaction with person(s) of any age that is perpetrated (a) against the victim's will (b) without consent or (c) in an aggressive, exploitative, manipulative, or threatening manner' which includes actions such as molesting, rape, voyeurism, exhibitionism, or 'obscene communications' which includes actions committed through the internet e.g. unwanted explicit pictures or messages (Ryan et al, 2010). Thus, a juvenile sexual offender can be defined as a legally categorised minor who commits any sexual act with a person of any age, against the victim's will, without consent, or in an aggressive, exploitative, manipulative, or threatening manner (Gerardin \& Thibaut, 2004). Ryan emphasises, however, that this definition is not always easily transferable in relation to juveniles with issues regarding peer-to-peer relationships for example which have resulted in juveniles being exposed to charges of child pornography and/or sexual relations with a minor (Ryan et al, 2010). Ryan calls for further exploration into juvenile sexual offending and the way in which it is legislated, particularly in the area of peer-to-peer relationships, adding that particular attention needs to be paid to the concepts of consent, equality, and coercion (ibid).

Juvenile sexual offending has traditionally been under researched and to date there has been a dearth of EU wide comparative research. The lack of robust and comparative data has led to sometimes conflicting scholarly reports, for example, Aebi et al (2012) report that some studies suggest the need for specialised treatment for juvenile sexual offenders due to the differences setting them apart from general delinquents, while other studies found that specialised intervention is not needed and suggest that family and social intervention may be more successful. Aebi et al (2012) concluded simply, that more research needed to be conducted in the area.

Some scholars have highlighted the rise in internet usage, Fortin and Paquette (2018) note that by 2015 almost half of the world's population was connected to the internet, as having led to a new form of juvenile sexual offending and this change potentially leading to a rise in prevalence in the area (Neto, 2013). Durkin (1997) outlines three ways in which the internet can be taken advantage of by sexual offenders; to access images for personal use, to connect with other sexual offenders and thirdly, to engage in inappropriate communication directly with 
children. The potential impact of the internet on this space has led to increased discussions on the role of over sexualising young people at a very young age and the ease of sharing problematic material (Enson,2018). More recently Ireland has enacted new laws in the area of sharing images which will impact this space (Harassment, Harmful Communications and Related Offences Act 2020). Moreover, a reporting unit, supported by the Irish Department of Justice, was launched in 1999 and provides a platform (hotline.ie) where the public can report illegal content online, especially child sexual abuse material. In 2019 hotline.ie reported its highest figures to date, with 1 in 4 of the 10,773 cases reported by the public being classified as child sexual abuse material. This was a $79 \%$ increase on 2018, related to 62 domains and spanned 32 countries worldwide (Hotline Annual Report, 2019). These numbers reflect the ease of access to inappropriate content on the internet for sexual abusers and the potential for increased sexualisation of young children. They also give rise to concerns over the consequences this may have in terms of young persons' engagement in risky sexual activity from consensual to non-consensual interactions (Massey et al, 2020). Durkin (1997) suggests that young children are especially vulnerable to non-consensual interactions over the internet, simply because they are often unaware of the implications of what they are being asked to do, an example being, a request for a young person to undress. Wolak et al. (2008) concede that more research is needed to clearly ascertain whether there exists a definite link between online content and offline offences. Moreover, the lack of data on whether there has been an increase in juvenile sexual offending and whether this is correlated with access to the internet or not, is preventing robust research in this area. Wolak, et al. (2010:111) argue that the reporting around internet abuse is "largely inaccurate" and that data is sometimes misrepresented; incidents are sometimes recorded as sexual assault where in reality they qualify as statutory rape, with the crime taking place due to a lack of education on the part of the victim, as well as the predatory nature of the offender.

Currently, prevalence research suggests that those under 18 years of age carry out roughly 15 to $20 \%$ of all sex offense, with sex offenses against children increasing to roughly $50 \%$ of cases involving juvenile offenders (Ryan, 2016). Others report that $20 \%$ of rapes are perpetuated by those under 18 years of age, with $25 \%$ of those being suspected of having committed multiple sexual offences (Van Wijk et al, 2009). In addition to this, the Irish criminal justice system saw an increase of $20 \%$ in sexual offences carried out by juveniles in 2017 in comparison to the year prior (Garda Youth Diversion \& Crime Prevention Bureau, 2017). This rate translated into $35 \%$ of the total sexual offences carried out in Ireland in that year (ibid). In Canada, it was found that youth were the perpetrators of roughly $17 \%$ of sexual offences in 2014, though it is important to note the category of 'youth' includes individuals up to 24 years of age (Allen\& Superle, 2016). In Australia, it was found that, depending on the state, 9 to $16 \%$ of sexual offences involved a juvenile offender (Boyd \& Broomfield, 2006). However, due to the various methodologies used to collect the data it is difficult to conduct any robust comparative analysis. This study aims to fill this gap by conducting a comparative study that will collect comparative prevalence data from across all EU Member States. EU wide comparative research is important due to the ability for each Member State to knowledge share and learn from each other, controlling for various divergences across the States and cultural variation. Nelken (2009) views comparative research as a way in which to compare and contrast approaches and responses to crimes across jurisdictions. It also provides an opportunity to learn from practices elsewhere in a bid to improve the current approach in the jurisdiction within which the research is being undertaken (ibid). In regard to this study, Nelken's warning against approaching comparative research and data in an overly ethnocentric manner or, on the other hand, an overly relativistic manner has been taken on board (ibid). This study will also catalogue sexual offender programmes aimed at juvenile offenders and any other interventions used for this cohort of offender so as to gain a better understanding of current state responses

Social Science Protocols, July 2021, 1-8.

http://dx.doi.org/10.7565/ssp.v4.5353 
in this area. This project therefore should be understood as developing a foundational framework from which other research can be conducted.

\section{Methods/Design}

\subsection{Research Design}

This project will use an online survey to collect data on juvenile sexual offending prevalence rates and state interventions/responses to juveniles accused/convicted of a sexual offence. The survey will consist of both closed ended questions and open ended questions. The closed ended questions will be used primarily to collect prevalence figures related to four types of juvenile offending. These data will be collected for both male and female offenders and will be categorised according to the age of the offender at the time of the offence. Furthermore, the survey will collect data over a 10 year period ( $1^{\text {st }}$ Jan 2009- $30^{\text {th }}$ Dec 2018). The open ended questions will collect some contextual data to assist with understanding the prevalence data for example, the legal age of a juvenile across each jurisdiction, the age of criminal responsibility across each jurisdiction, counting rules and any changes to counting rules across each jurisdiction, and so on.

To construct the survey in a manner that allowed for the collection of comparative data it was necessary to develop a typology of offences. This was necessary to ensure that the data collected related to the same offence across each jurisdiction. The four types developed were sexual offending as a broad category, non-contact sexual offences (exhibitionism, frotteurism, sexual harassment and unsolicited use of personal images [these can have occurred online]), non-penetrative sexual assault, and penetrative sexual assault. Whilst it is accepted that there are nuances within these types it is beyond this study to explore these and it is proposed that this first step of categorisation of the data will allow for further research that can delve into these types more deeply.

The typology was developed through a strategic review of the literature that used key words to conduct a literature search using Google scholar. The key words used were juvenile sexual offending; juvenile sexual deviancy; juvenile sexual delinquency; juvenile sexual offenders characteristics; and juvenile offenders sexual recidivism and the initial search resulted in over 100,000 articles. These key words were chosen because of their relevance to the nature of youth offending, both in a general and sexual context.

The articles were then reviewed for their relevance to the typology development using inclusion and exclusion criteria (see Figure 1). The primary focus was on articles based on descriptive accounts of offences engaged in by juveniles.

Figure 1. Inclusion and exclusion criteria used when selecting articles for the typology development.

\begin{tabular}{ll}
\hline Inclusion & Exclusion \\
\hline Juvenile sexual offending & Adult sexual offenders \\
EU data on juvenile sexual offending & Data outside the EU \\
Definitions of juvenile sexual offences & \\
Recidivism data & \\
\hline
\end{tabular}

Following the review of the literature, sixty-two articles were deemed relevant to the development of the evidence-based typology. These articles were reviewed to explore the grouping of offences into categories and these categories were then utilised to develop the typology. Once the typology was developed it was shared with the projects external advisors group and all feedback from the external advisors group was then incorporated into the

Social Science Protocols, July 2021, 1-8. 
typology. The external advisors consisted of judges, lawyers, police officers, NGOs and academics. The typology was then used to guide the development of the study survey, which will collect prevalence data on each type of offence listed in the typology (online, exposure, indecent exposure, non-penetrative sexual assault and penetrative sexual assault).

The survey will initially be sent to each EU member state's Department of Justice (n:27) and child welfare agency (n:27), totalling (n:54). They will be asked to provide details of any other agency that collects data on juvenile sexual offending in their country to ensure that the correct agency is contacted for data collection. Upon return of the survey the quantitative data will be entered into SPSS for frequency and descriptive analysis and the qualitative data will be analysed using categorical coding using excel to explore each countries response to the same question. This can then be explored more deeply for convergence/divergence and to assist with providing contextual data for the interpretation of the quantitative data.

\subsection{Limitations}

One limitation is the 'dark figures' of juvenile sexual offending. The dark figures accounts for the level of unreported offences in a jurisdiction. Taking this problem into account, the data we find may not reflect the full scale of the issue of juvenile sexual offending, given that this particular offence type may go unreported. To overcome this limitation, it is recommended that a follow on study focus on collecting such figures as a means to complement our officially recorded figures.

A second limitation is the rigidity of the typology. It is accepted that the typology used in the study fails to account for the nuanced and complicated nature of the offences that fall within each type. However, this project is to be seen as a starting point to progress and conduct subsequent research in the area, unpicking the typology and delving deeper into the offending rates, their implication, and the states responses.

A third limitation was the lack of funds to take on a translator for the project. This resulted in the use of Google Translate to translate the research documents (surveys, letters of invitation, information sheets and consent forms) into the relevant languages before sending them to each EU state's Justice Department. This limitation was acknowledged in the invitations to participate that were sent to each country. Both the English language and foreign language version was included in the invitation to make it as easy as possible for recipients to understand and respond to the invitation.

\subsection{Quality assurance}

The research team will conduct fortnightly meetings via Zoom/Teams in order to maintain quality by sharing ideas and seeking feedback for our work amongst each other. The fortnightly meetings will allow us to keep track of the study's objectives, breaking targets down into regular short-term goals. We will also be conducting monthly meetings with our research partners, the Association of Criminal Justice Research and Development (ACJRD), from whom we will receive constructive feedback and suggestions on specific points. The ACJRD will also connect us with relevant criminal justice practitioners (judges, garda representatives, solicitors etc.) who themselves can offer useful feedback based on their experience of working in the juvenile justice area. The minutes of all meetings will be recorded, written and uploaded to OneDrive files where the research team can keep track of our records. The feedback taken from meetings will allow us to maintain a level of quality while the recording of minutes will ensure important details or ideas are not mistakenly omitted from our findings. 


\subsection{Duration of the project}

This project commenced in May 2020 and will conclude in December 2021.

\subsection{Ethics}

This project has been approved by the Maynooth University Ethics Committee (Tier 2).

\section{Discussion}

This is an important study due to the dearth of data, particularly comparable data, in the area of juvenile sexual offending. Without empirical data it is impossible to develop evidence led policy and practice, and difficult to move beyond anecdotal discourses in the public space. This project should be seen as a first step in laying an evidence based foundation from which further and more in-depth research can commence. For example, it is very difficult to determine whether there is a need for specially designed intervention programmes for juvenile sexual offenders to meet the need of increased offending in the area, due to conflicting data on prevalence rates. Furthermore, it is very difficult to explore evaluations of juvenile sexual offenders' intervention programmes and their applicability to a different jurisdiction without having an evidence based understanding of the guiding mechanisms (ages of criminal responsibility etc.), current rates of offending, and the approaches being adopted to deal with such offending (diversion etc.). This project aims to provide the required data to commence a comprehensive evidence based literature from which further, more complex and more in-depth comparable research can commence. Comparable research has the potential to facilitate the generation of shared learnings from across the EU and thus build a shared knowledge base in this area.

\section{Declarations}

Availability of data and material: The outputs from this project will be made available on the Maynooth University Research Archive Library MURAL

Competing interests: The authors declare that there is no conflict of interest

Funding: This project was funded by the Irish Research Council New Foundations Scheme ${ }^{1}$

Authors' contributions: Dr Quigley designed the research project and all authors contributed to the design and drafting of the project protocol.

Acknowledgements: The authors would like to acknowledge the Irish Research Council for the support provided to this research project.

\footnotetext{
${ }^{1}$ https://research.ie/

Social Science Protocols, July 2021, 1-8. 


\section{References}

Aebi, M., Vogt, G., Plattner, B., Steinhausen, H. C., \& Bessler, C. (2012). Offender types and criminality dimensions in male juveniles convicted of sexual offenses. Sexual abuse, 24(3), 265-288. https://doi.org/10.1177\%2F1079063211420449

Allen, M. K., \& Superle, T. (2016). Youth crime in Canada, 2014. Juristat: Canadian Centre for Justice Statistics, 1, 3-15. https://www150.statcan.gc.ca/n1/en/pub/85-002x/2016001/article/14309-eng.pdf?st=9wqEvYkQ

Antonopoulos, I., Dingwall, G., \& Hillier, T. (2018). The continuing chronology of confusion: crime prevention, welfare and the why of youth justice. The Journal of Criminal Law, 82(5), 402-419. https://doi.org/10.1177\%2F0022018318790135

Berryessa, C. M., \& Reeves, J. (2020). The Perceptions of Juvenile Judges Regarding Adolescent Development in Evaluating Juvenile Competency. The Journal of Criminal Law and Criminology 110(3), 551-592. https://www.jstor.org/stable/48573790

Boyd, C. R., \& Bromfield, L. (2006). Young people who sexually abuse: Key issues. Melbourne: Australian Institute of Family Studies.1, 1-13. https://citeseerx.ist.psu.edu/viewdoc/download?doi=10.1.1.529.4697\&rep=rep1\&type=pdf

Durkin, K. F. (1997). Misuse of the Internet by pedophiles: Implications for law enforcement and probation practice. Fed. Probation, 61 (3), 14-18. https://www-proquestcom.jproxy.nuim.ie/trade-journals/misuse-internet-pedophiles-implicationslaw/docview/213983006/se-2?accountid=12309

Dünkel, F. (2014). Juvenile Justice Systems in Europe-Reform developments between justice, welfare and 'new punitiveness'1. Kriminologijos studijos, 10, 31-76. https://doi.org/10.15388/CrimLithuan.2014.1.3676

Enson, S. (2018). Digital technology and the internet: Exploring the risks to children and young people. British Journal of School Nursing, 13(2), 72-76. https://doi.org/10.12968/bjsn.2018.13.2.72

Fortin, F. and Paquette, S. (2018). 'Online Sexual Exploitation of Children: reactive and proactive policing', in Lussier, P., \& Beauregard, E. (Eds.). Sexual offending: A criminological perspective. Routledge. https://doi.org/10.4324/9781315522692

Garda Youth Diversion and Crime Prevention Bureau, (2017). Annual report of the committee appointed to monitor the effectiveness of the diversion programme. Dublin: An Garda Siochana.

http://www.iyjs.ie/en/IYJS/2017\%20Annual\%20Report\%20of\%20Monitoring\%20Commi ttee\%20(English).pdf/Files/2017\%20Annual\%20Report\%20of\%20Monitoring\%20Commi ttee\%20(English).pdf

Gerardin, P., \& Thibaut, F. (2004). Epidemiology and treatment of juvenile sexual offending. Pediatric Drugs, 6(2), 79-91. https://doi.org/10.2165/00148581-20040602000002

Massey, K., Burns, J., \& Franz, A. (2020). Young people, sexuality and the age of pornography. Sexuality \& Culture, 25, 318-336. https://doi.org/10.1007/s12119-02009771-z

Nelken, D. (2009). Comparative criminal justice: Beyond ethnocentrism and relativism. European Journal of Criminology, 6(4), 291-311. https://doi.org/10.1177\%2F1477370809104684

Ryan, G., Leversee, T. F., \& Lane, S. (2011). Juvenile sexual offending: Causes, consequences, and correction. John Wiley \& Sons.

Shen, F. X. (2012). Legislating Neuroscience: the case of juvenile justice. Loyola of Las Angeles Law Review 46 (3), 985-1018. https://digitalcommons.lmu.edu/llr/vol46/iss3/5 
Van Wijk, A., Vermeiren, R., Loeber, R., Hart-Kerkhoffs, L. T., Doreleijers, T., \& Bullens, R. (2006). Juvenile sex offenders compared to non-sex offenders: A review of the literature 1995-2005. Trauma, Violence, \& Abuse, 7(4), 227-243. https://doi.org/10.1177\%2F1524838006292519

Vitacco, M. J., Caldwell, M., Ryba, N. L., Malesky, A., \& Kurus, S. J. (2009). Assessing risk in adolescent sexual offenders: recommendations for clinical practice. Behavioral Sciences \& The Law, 27(6), 929-940. https://doi.org/10.1002/bsl.909

Wolak, J., Finkelhor, D., Mitchell, K. J., \& Ybarra, M. L. (2010). Online "predators" and their victims: Myths, realities, and implications for prevention and treatment. Psychology of Violence, 1(S), 13-35. https://doi.org/10.1037/2152-0828.1.S.13 